\title{
Utilization Pattern of Antipsychotics at a Tertiary Care Hospital in Oman
}

\author{
Mohammed Al Za'abi ${ }^{*}$, Ahmed S Al-Hinai and Salim A Al-Busaidi
}

Department of Pharmacology \& Clinical Pharmacy, College of Medicine \& Health Sciences, Sultan Qaboos University, Muscat, Oman

*Corresponding author: Mohammed Al Za'abi, Department of Pharmacology and Clinical Pharmacy, College of Medicine and Health Sciences, Sultan Qaboos University, P. O. Box 115 Al Khod, Postal code 123, Oman, Tel: 9682414 1107; E-mail: zaabi@squ.edu.om

Received Date: August 26, 2014, Accepted Date: October 15, 2014, Published Date: October 21, 2014

Copyright: $\odot$ 2014, Mohammed Al Za'abi et al., This is an open-access article distributed under the terms of the Creative Commons Attribution License, which permits unrestricted use, distribution, and reproduction in any medium, provided the original author and source are credited.

\begin{abstract}
Introduction: Antipsychotics, classified into typical and atypical, are a corner stone in the treatment of schizophrenia. Their use varies among countries due factors such as cost, efficacy and side effects. Little information is known about the use of these agents in the developing countries.

Objective: To describe the utilization pattern of antipsychotics among adult patients attending Sultan Qaboos University Hospital (SQUH), a tertiary care hospital in Oman.

Method: Data from January to March 2013 for patient prescribed antipsychotics at SQUH was retrieved retrospectively after obtaining ethical approval.

Results: Among 535 analyzed records, females accounted for $57.3 \%$ of prescriptions and the age group between 18 to 39 years constitutes the major $(54.7 \%)$ utilizer of antipsychotics. Atypical antipsychotics accounted for $68.8 \%$ of prescriptions. Olanzapine was the most common prescribed atypical drug $(48.1 \%)$ while haloperidol was the most utilized (34.1\%) typical agent. Schizophrenia was the main indication for the use of antipsychotics (26.9\%) followed by depressive disorders (23.2\%) and bipolar affective disorder (11.6\%). Monotherapy accounted for the majority $(93.0 \%)$ of prescriptions.
\end{abstract}

Conclusion: At SQUH atypical antipsychotics accounted for the majority of antipsychotic prescriptions which is in-line with most standard therapeutic guidelines recommendations for the treatment of psychotic disorders. Further research exploring the tolerability and outcome of such treatment is needed.

Keywords: Antipsychotics; Schizophrenia; Olanzapine; Haloperidol

\section{Introduction}

Antipsychotics are the mainstay agent for the treatment of schizophrenia and other psychotic disorders. They are categorized into typical (first generation) and atypical (second generation) agents. There is a variation in the prescribing pattern of these two categories across different part of the world, particularly with respect to the medications favored within each category [1-3]. The variation is attributed to various factors such as side-effects profile, patients' characteristics, concomitant diseases and cost [1-5]. However, the major factor that affects the prescribing trends of these antipsychotics among developed and developing countries is the cost despite treatment guidelines recommendation where atypical antipsychotics are considered as the first pharmacologic option for schizophrenia [5-8]. In East Asian region (China, Hong Kong, Japan, Singapore and Taiwan) and among 2368 patients, $44 \%$ were receiving a single antipsychotic agent and half of these agents (53.3\%) were typical ones [5] In Australia, however, the atypical drugs were the most used antipsychotics (77.3\%) and olanzapine was the most prescribed drug [9].

In Oman, as with the rest of the developing world, there is scant data and no documented study about the utilization pattern of antipsychotics, despite the annual increase in the incidence of mental disorders by $8.4 \%$ from 2010 to 2011 , with total number of 78,559 cases in 2011 [10]. Therefore, the aim of this study is to describe the prescribing pattern of antipsychotic medications in adult patients at a tertiary care hospital in Oman.

\section{Methods}

This retrospective study was conducted at Sultan Qaboos University hospital (SQUH), a tertiary health care facility in Oman. The database of adult ( $\geq 18$ years) patients receiving antipsychotics medications where retrieved from electronic patient records "TrakCare", the Hospital Information System, in the period of January to March 2013. A standard data collection form was used to collate information about demographic characteristics such as sex, age and weight; data about disease such as type of disease, comorbidities and duration and data about medications such as type, concomitant drugs and recorded side effects. In addition, the biochemical markers for glucose level and lipid profile were collected.

An ethical approval was sought and obtained from the Medical Ethics Committee at Sultan Qaboos University before conducting the study.

\section{Statistical Analysis}

For categorical variables, frequencies and percentages were reported. For continuous variables, mean and standard deviation were used to summarize the data. Statistical analyses were performed using 
Citation: Al Za'abi M , Al-Hinai SA, A Al-Busaidi S (2014) Utilization Pattern of Antipsychotics at a Tertiary Care Hospital in Oman. J Psychiatry 17:

Page 2 of 5

Statistical Package of Social Sciences version 15 (SPSS, Inc., Chicago, IL, USA).

\section{Results}

A total number of 535 patients were recruited. Their mean age was $41.3 \pm 15.9$ years with a range of $18-98$ years. The male to female sex ratio was 0.74 : 1.0. More than half of the patients (54.7\%) were between the ages of 18 to 39 years (Table 1 ).

\begin{tabular}{|c|c|c|c|c|}
\hline & & $\mathbf{N}$ & Typical & Atypical \\
\hline \multicolumn{5}{|l|}{ Sex } \\
\hline & M & 224 & 62 & 162 \\
\hline & $\mathrm{F}$ & 301 & 95 & 206 \\
\hline \multicolumn{5}{|l|}{ Age (years) } \\
\hline & $18-28$ & 115 & 35 & 80 \\
\hline & $29-38$ & 154 & 44 & 110 \\
\hline & $39-48$ & 95 & 35 & 60 \\
\hline & $49-59$ & 76 & 21 & 55 \\
\hline & $\geq 60$ & 85 & 22 & 63 \\
\hline \multicolumn{5}{|l|}{ Duration (years) } \\
\hline & $1-5$ & 277 & 31 & 246 \\
\hline & $6-10$ & 176 & 78 & 98 \\
\hline & $>10$ & 25 & 15 & 10 \\
\hline & Unknown & 47 & 33 & 14 \\
\hline \multicolumn{5}{|l|}{ Co-morbidities } \\
\hline & None & 307 & 94 & 213 \\
\hline & Diabetes \& Hypertension & 28 & 19 & 9 \\
\hline & Epilepsy & 6 & 3 & 3 \\
\hline & Asthma & 4 & 1 & 3 \\
\hline & Others & 21 & 8 & 13 \\
\hline & No reports & 159 & 32 & 127 \\
\hline \multicolumn{5}{|c|}{ Concomitant drugs } \\
\hline & None & 60 & 20 & 40 \\
\hline & Central Nervous Agents & 352 & 86 & 266 \\
\hline & Antimuscuranic & 71 & 30 & 41 \\
\hline & Cardiovascualr & 50 & 24 & 26 \\
\hline & Others & 78 & 23 & 55 \\
\hline
\end{tabular}

Table 1: Gender, age, disease duration, co-morbidities and concomitant drug use of studied population $(\mathrm{N}=525)$

More than two thirds of the patients $(368,68.8 \%)$ were prescribed haloperidol was used in 57 (34.1\%) of patients followed by atypical antipsychotics while the rest were on typical antipsychotics chlorpromazine (38,22.8\%), prochlorperazine (31,18.6\%) and $(157,29.3 \%)$ and lithium (10,1.9\%). The most used atypical agent was trifluoperazine (15, 9.0\%) (Table 2).

olanzapine $(177,48.1 \%)$ followed by risperidone $(125,34.0 \%)$, aripiprazole $(55,15.4 \%)$ and clozapine $(8,2.2 \%)$. For typical ones 
Page 3 of 5

Single antipsychotic drug use account for the majority of prescription (93.0\%). Added typical and atypical antipsychotic to treatment regimen accounted for $3.2 \%$ and $3.8 \%$ of prescription, respectively.

The most common indication for use of antipsychotics was schizophrenia $(132,25.1 \%)$ followed by depressive disorders (114, $21.7 \%)$ and bipolar affective disorder (60,11.4\%). Other indications included nausea and vomiting, dizziness, epilepsy, dementias and others (Table 2).

The most concomitant drugs are those affecting central nervous system (CNS) $(352,63.9 \%)$ followed by anti-muscarinic drugs (71, $12.9 \%$ ) (Table 1).
Among co-morbidities, diabetes and hypertension were the highest $(28,47.5 \%)$ followed by epilepsy $(6,10.2 \%)$ and asthma $(4,6.8 \%)$ (Table $1)$.

Data about side effects were not reported in the majority of patients (458, 85.6\%). Few patients reported weight gain while on antipsychotics $(77,14.4 \%)$. Similarly effect of antipsychotics on glucose or lipid profile could not be retrieved due to lack of data.

\begin{tabular}{|c|c|c|c|c|c|c|c|c|c|c|}
\hline & & N & Schizophrenia & $\begin{array}{l}\text { Depressive } \\
\text { Disorders }\end{array}$ & $\begin{array}{l}\text { Bipolar } \\
\text { Disorder }\end{array}$ & Dementia & Dizziness & $\begin{array}{l}\text { Nausea \& } \\
\text { Vomiting }\end{array}$ & Others & Not Reported \\
\hline \multirow[t]{8}{*}{ Typical } & & 157 & 34 & 31 & 10 & 5 & 15 & 16 & 23 & 25 \\
\hline & Haloperidol & 57 & 15 & 10 & 5 & 5 & - & - & 8 & 14 \\
\hline & $\begin{array}{l}\text { Chlorpromaz } \\
\text { ine }\end{array}$ & 38 & 9 & 8 & 2 & - & 1 & 2 & 9 & 9 \\
\hline & $\begin{array}{l}\text { Prochlorpera } \\
\text { zin }\end{array}$ & 31 & - & 3 & - & - & 14 & 14 & - & - \\
\hline & $\begin{array}{l}\text { Trifluoperazi } \\
\text { ne }\end{array}$ & 15 & 3 & 7 & - & - & - & - & 3 & 2 \\
\hline & Flupentixol & 8 & 1 & 3 & 1 & - & - & - & 3 & - \\
\hline & Fluphenazin & 4 & 4 & - & - & - & - & - & - & - \\
\hline & $\begin{array}{l}\text { Zuclopenthix } \\
\text { ol }\end{array}$ & 4 & 2 & - & 2 & - & - & - & - & - \\
\hline \multirow[t]{5}{*}{ Atypical } & & 368 & 98 & 83 & 50 & 7 & 2 & - & 76 & 52 \\
\hline & Olanzapine & 177 & 46 & 42 & 30 & 4 & 2 & - & 30 & 23 \\
\hline & Risperidone & 125 & 33 & 26 & 13 & 2 & - & - & 32 & 19 \\
\hline & Aripiprazole & 57 & 14 & 15 & 5 & 1 & - & - & 13 & 9 \\
\hline & Clozapine & 9 & 5 & - & 2 & - & - & - & 1 & 1 \\
\hline
\end{tabular}

Table 2: Indications for the use of antipsychotics drugs $(\mathrm{N}=525)$

\section{Discussion}

This study offers an insight into the trend of prescribing pattern of antipsychotics in Omani population and perhaps the region. It also forms a database for future research and pattern comparison. The ratio for use of atypical: typical antipsychotics in our study (2.3:1) is somehow similar to what is reported in Western world and higher than other developing countries [5,9,11-14]. One reason for this might be attributed to the economic status of the countries. Due to their efficacy and low side effects profile atypical antipsychotics are considered in most standard guidelines to be the first line pharmacologic treatment for schizophrenia [15-17]. However, as they are much more expensive than typical antipsychotics and as the treatment of schizophrenia with antipsychotics needs to be long life for some patients, their use in countries with low economical income is low $[2,5,8,18]$. For such reason, even in the early 2000s in the United States, there was a variation in the utilization of typical and atypical antipsychotics among different ethnic groups [19].
The continuing use of typical antipsychotic in our population especially to new cases can be due to contraindications for use of atypical ones, such as for patients with high risk of diabetes. Furthermore, those patient who been using typical antipsychotics for long time and showed improvements with their use will still continue to be prescribed the same drugs unless they show adverse effects or decrease effect/improvement with drug.

In contrary to other studies, females were found to be the most utilizer of antipsychotics in our study [5,6,11-14]. This may be due to the higher incidence and prevalence of mental health morbidities as well as the total visits in psychiatric clinics among females than males as reported in the annual report of Ministry of Health in Oman $(\mathrm{MOH})[10]$.

The age distribution between 20 to 50 years was the major consumer $(68 \%)$ for antipsychotic drugs. The annual report of $\mathrm{MOH}$ in Oman described that the age from 20 to 44 years has the highest 
Page 4 of 5

prevalence and incidence of mental health morbidities [10]. This was somehow similar to what was reported in East Asia where the mean age was $43.6+/-12.5$ years [5].

Olanzapine was the most common prescribed atypical antipsychotic drug. This finding is similar to reports conducted in Canada and Hong Kong $[5,13]$. In China clozapine was the most used atypical agent but in SQUH it was the least used atypical antipsychotics drug [5]. This difference might be due to the physician preferences and availability of generic versus brand choices. For typical antipsychotics, haloperidol followed by chlorpromazine was the commonest used agents in SQUH, which is also similar to the Canadian and Australian studies $[9,11]$. Both drugs are included as essential medicines used in psychotic disorders by WHO [20]. Haloperidol was the main drug used in schizophrenia in our study, while chlorpromazine was the main agent for this indication in other countries $[6,14]$.

The most common indication $(132,25.1 \%)$ for use of both atypical and typical antipsychotics was schizophrenia. This is in-line with most guidelines recommendation $[4,8]$. Other uses included depressive disorders $(114,21.7 \%)$ and bipolar affective disorder $(60,11.4 \%)$. Some agents such as prochlorperazine were primarily used for nausea, vomiting and dizziness. About $15 \%$ of inductions for the use of antipsychotics were not labeled in patient's records and thus they were not used in analysis.

The use of a single antipsychotic was found in $93.0 \%$ of patients. This pattern is similar to most of studies [11-14]. The most concomitant drugs given along with antipsychotics are those affecting CNS. Patients with psychiatric disorders might also suffer from other mental/brain related conditions thus the use of drugs affecting CNS. The second common concomitant drugs were anti-muscarinic drugs. Although atypical antipsychotics are known to be less associated with muscarinic side effects than typical ones but they are not totally devoid of such side effects and this might explain the prescribing of these agents in our patients.16 Furthermore some other comorbid conditions might require the use of anti-muscarinic drugs such as dizziness and dementia.

Diabetes mellitus and hypertension were the most common comorbidities reported in our patients. It is possible that this might be the cause for the contraindication of prescribing atypical antipsychotics, been a side effect of antipsychotics or just co-incidence [21-22]. However, we were not able be judged the relation because no clear time relation data were available.

The antipsychotics, both typical and atypical, can cause weight gain, though it is more common with atypical antipsychotics [23-24]. However, data about weight was missing from majority of our patient records. This might be due either the irregular measurement of weight in their records or no follow up of weight is carried out by the treating physicians.

\section{Limitations}

Although this the first report exploring the utilization of antipsychotics in Oman, however, there are several limitations to it. First, as with any retrospective study some data were not available to make conclusion especially with treatment outcome, doses, tolerability, and side effects. Second, we could not follow up patients records to determine if atypical antipsychotics being prescribed as first line or as replacement for typical ones. Third the utilization of these agents at SQUH might not represent all Oman and thus extending the results to all country cannot be made with confidence.

\section{Conclusion}

This survey have showed that the atypical antipsychotics olanzapine and risperidone constitutes more than one third (35.3\%) of antipsychotic prescriptions. Almost all patients received one antipsychotic agent in keeping with most standard therapeutic guidelines. Further studies are required to examine the outcome of these prescription and their effects on metabolic and other physiologic profiles of patients.

\section{Declaration}

The authors declare that they have no conflict of interest to disclose. We confirm that we have read the journal position on issues involved in ethical publication and affirm that this report is consistent with these guidelines.

\section{References}

1. Gardner DM, Baldessarini RJ, Waraich P (2005) Modern antipsychotic drugs: a critical overview. CMAJ 172: 1703-1711.

2. Leucht S, Corves C, Arbter D, Engel RR, Li C, et al. (2009) Secondgeneration versus first-generation antipsychotic drugs for schizophrenia: a meta-analysis. Lancet 373: 31-41.

3. Miyamoto S, Duncan GE, Marx CE, Lieberman JA (2005) Treatments for schizophrenia: a critical review of pharmacology and mechanisms of action of antipsychotic drugs. Mol Psychiatry 10: 79-104.

4. Gadelha A, Noto CS, de Jesus Mari J (2012) Pharmacological treatment of schizophrenia. Int Rev Psychiatry 24: 489-498.

5. Chong MY, Tan CH, Fujii S, Yang SY, Ungvari GS, et al. (2004) Antipsychotic drug prescription for schizophrenia in East Asia: rationale for change. Psychiatry Clin Neurosci 58: 61-67.

6. Xiang YT, Weng YZ, Leung CM, Tang WK, Ungvari GS (2007) Clinical and social determinants of antipsychotic polypharmacy for Chinese patients with schizophrenia. Pharmacopsychiatry 40: 47-52.

7. Leucht S, Cipriani A, Spineli L, Mavridis D, Orey D, et al. (2013) Comparative efficacy and tolerability of 15 antipsychotic drugs in schizophrenia: a multiple-treatments meta-analysis. Lancet 382: 951-962.

8. Gaebel W, Weinmann S, Sartorius N, Rutz W, McIntyre JS (2005) Schizophrenia practice guidelines: international survey and comparison. Br J Psychiatry 187: 248-255.

9. Hollingworth SA1, Siskind DJ, Nissen LM, Robinson M, Hall WD (2010) Patterns of antipsychotic medication use in Australia 2002-2007. Aust N Z J Psychiatry 44: 372-377.

10. Annual health report (2010/2011). Ministry of Health: Muscat, Oman.

11. Kamble P, Chen H, Sherer JT, Aparasu RR (2009) Use of antipsychotics among elderly nursing home residents with dementia in the US: an analysis of National Survey Data. Drugs Aging 26: 483-492.

12. Park SC, Lee MS, Kang SG, Lee SH (2014) Patterns of antipsychotic prescription to patients with schizophrenia in Korea: results from the health insurance review \& assessment service-national patient sample. J Korean Med Sci 29: 719-728.

13. Hagen B, Esther CA, Ikuta R, Williams RJ, Le Navenec CL, et al. (2005) Antipsychotic drug use in Canadian long-term care facilities: prevalence, and patterns following resident relocation. Int Psychogeriatr 17: 179-193.

14. Sweileh W, Jaradat N, Al-Khayyat AA (2004) Typical and Atypical Antipsychotic Drug Utilization in a Psychiatric Clinic in Palestine. AnNajah Univ J Res 18: 39-47.

15. Uçok A, Gaebel W (2008) Side effects of atypical antipsychotics: a brief overview. World Psychiatry 7: 58-62. 
Citation: Al Za'abi M , Al-Hinai SA, A Al-Busaidi S (2014) Utilization Pattern of Antipsychotics at a Tertiary Care Hospital in Oman. J Psychiatry 17: 1000171. doi:10.4172/2378-5756.1000171

Page 5 of 5

16. Divac N, Prostran M, Jakovcevski I, Cerovac N (2014) Second-generation antipsychotics and extrapyramidal adverse effects. Biomed Res Int 2014: 656370 .

17. Keks N, Mazumdar P, Steele K (2000) The new antipsychotics. How much better are they? Aust Fam Physician 29: 445-450

18. dosReis S, Johnson E, Steinwachs D, Rohde C, Skinner EA, et al. (2008) Antipsychotic treatment patterns and hospitalizations among adults with schizophrenia. Schizophr Res 101: 304-311.

19. Daumit GL, Crum RM, Guallar E, Powe NR, Primm AB, et al. (2003) Outpatient prescriptions for atypical antipsychotics for African Americans, Hispanics, and whites in the United States. Arch Gen Psychiatry 60: 121-128.

20. WHO. Essential Medicines 18th edition. WHO Model List 2013.
21. Smith M, Hopkins D, Peveler RC, Holt RI, Woodward M, et al. (2008) First- v. second-generation antipsychotics and risk for diabetes in schizophrenia: systematic review and meta-analysis. Br J Psychiatry 192: 406-411.

22. Dixon L, Weiden P, Delahanty J, Goldberg R, Postrado L, et al. (2000) Prevalence and correlates of diabetes in national schizophrenia samples. Schizophr Bull 26: 903-912.

23. Allison DB, Mentore JL, Heo M, Chandler LP, Cappelleri JC, et al. (1999) Antipsychotic-induced weight gain: a comprehensive research synthesis. Am J Psychiatry 156: 1686-1696.

24. Stigler KA, Potenza MN, Posey DJ, McDougle CJ (2004) Weight gain associated with atypical antipsychotic use in children and adolescents: prevalence, clinical relevance, and management. Paediatr Drugs 6: 33-44. 